\title{
МЕРЫ ГОСУДАРСТВЕННОЙ ПОЛИТИКИ В ОТНОШЕНИИ МАЛОГО БИЗНЕСА ПО ВОПРОСАМ ЗАНЯТОСТИ НАСЕЛЕНИЯ САМАРСКОЙ ОБЛАСТИ *
}

\author{
(c) 2020 Боровицкая М.В. \\ кандидат экономических наук, доцент Департамента бизнес-аналитики \\ Финансовый университет при Правительстве Российской Федерации, Россия, Москва \\ E-mail: MVBorovitskaya@fa.ru \\ (c) 2020 Шнайдер В.В. \\ кандидат экономических наук, доцент департамента магистратуры (бизнес-программ) \\ Тольяттинский государственный университет, Россия, Тольятти \\ E-mail: gerutti1881@mail.ru \\ (c) 2020 Хмара Д.С.
}

кандидат экономических наук, доцент кафедры экономики судостроительной промышленности Санкт-Петербургский государственный морской технический университет, Россия, Санкт-Петербург

E-mail:dskhmara@yandex.ru

В последние годы остро обострилась проблема безработицы в нашей стране. Это связано со многими факторами, среди которых наиболее значимыми являются, экономические санкции со стороны ведущих европейских государств, непростая политическая и эпидемиологическая обстановка в мире. Все это, несомненно, негативным образом влияет на экономику России, влечет за собой сбои в работе отечественных предприятий, рост безработицы.

Статья посвящена рассмотрению вопросов решения проблемы безработицы и мерам государственной политики России в отношении малого бизнеса с целью повышения занятости населения на примере Самарской области.

Авторы подчеркивают, что от того, насколько трудоспособное население страны занято в деятельности государственных производственных предприятий, в сельскохозяйственном агрохолдинге, задействовано в развитии малого предпринимательства, зависит степень благосостояния этой страны, эффективность осуществляемых экономических и социальных преобразований.

В статье рассмотрены государственные программы по содействию занятости населения и регулированию социально-трудовых отношений в Самарской области. Основные направления государственной поддержки предпринимательства в Самарской области включают в себя развитие экспорта, содействие предприятиям производственного и инновационного характера, оказание ряда услуг субъектам малого и среднего предпринимательства, развитие моногородов, предпринимательство и пропаганда среди молодежи, а также оказание микрофинансовой поддержки бизнесу.

На основе мониторинга государственных программ поддержки населения в сфере занятости Самарской области, авторы конкретизировали меры, которые предпринимают региональные фонды финансовой поддержки субъектов МСП, обеспечивающие доступ субъектов малого и среднего предпринимательства к финансовым ресурсам.

Авторы отмечают, что государственная политика в отношении малого бизнеса в России с целью повышения занятости населения в настоящее время активно проводится. Разрабатываются и внедряются различные государственные программы по поддержке (финансовой, консультационной и т.д.) малого и среднего бизнеса, создаются новые рабочие места, сокращается уровень безработицы в стране.

Ключевые слова: безработица, трудовые ресурсы, рынок труда, трудоустройство, меры государственного регулирования занятости населения, самозанятость населения, механизмы в сфере занятости, микрофинансирование предпринимателей.

\footnotetext{
* Статья подготовлена по результатам исследований, выполненных за счет бюджетных средств по государственному заданию Финансового университета
} 
В последние годы остро обострилась проблема безработицы в нашей стране. Это связано со многими факторами, среди которых наиболее значимыми являются, экономические санкции со стороны ведущих европейских государств, непростая политическая и эпидемиологическая обстановка в мире. Все это, несомненно, негативным образом влияет на экономику России, влечет за собой сбои в работе отечественных предприятий, рост безработицы.

От того, насколько трудоспособное население страны занято в деятельности государственных производственных предприятий, в сельскохозяйственном агрохолдинге, задействовано в развитии малого предпринимательства, зависит степень благосостояния этой страны, эффективность осуществляемых экономических и социальных преобразований. В целях сокращения уровня безработицы постановлением правительства РФ от 15 апреля 2014 года N 298, утверждена и успешно реализуется государственная программа Российской Федерации «Содействие занятости населения» [1]. Ключевыми задачами данной программы являются задачи совершенствования механизмов и инструментов государственной тактики и стратегии на рынке труда.

Все регионы России активно включились в работу по претворению в жизнь государственной программы, не осталась в стороне и Самарская область.

Государственную политику в области развития и поддержки малого и среднего бизнеса в Самарской области осуществляет Министерство экономического развития, инвестиций и торговли Самарской области, департамент развития предпринимательства, входящий в структуру министерства наделен основными полномочиями.

В Самарской области реализуется государственная программа Самарской области «Развитие предпринимательства, торговли и туризма в Самарской области» на 2014-2030 годы (постановление Правительства Самарской области от 29.11.2013 № 699)» [1].

В настоящее время можно выделить несколько основных направлений государственной поддержки предпринимательству таких, как развитие экспорта, содействие предприятиям производственного и инновационного характера, оказание ряда услуг субъектам малого и среднего предпринимательства, развитие моногородов, предпринимательство и пропаганда среди молодежи, а также оказание микрофинансовой поддержки бизнесу.

В Самарской области функционирует развитая инфраструктура поддержки предпринимательства, включающая в себя муниципальные центры поддержки предпринимательства, институты финансовой поддержки, развития малых инновационных предприятий, организации информационно-консультационного обслуживания предпринимателей.

Компания, которая объединяет все меры поддержки малого и среднего предпринимательства - Федеральная корпорация по развитию малого и среднего предпринимательства. Корпорация вместе с регионами разрабатывает и внедряет единые правила поддержки компаниям, которые относятся к МСП, организует имущественную поддержку, проводит работу, которая направлена на рост доли закупок у малого и среднего бизнеса.

На базе Корпорации малого и среднего предпринимательства сформирована Национальная гарантийная система поддержки малого и среднего предпринимательства, объединяющая региональные гарантийные организации. В Самарской области такой организацией, которая обеспечивает гарантии и поручительства предпринимателям, является АО Микрокредитная компания «Гарантийный фонд Самарской области».

Существует 32 финансовые организации, они являются партнерами гарантийного фонда, через них происходит реализация программ по предоставлению поручительства субъектам малого и среднего предпринимательства. Условия поручительства таковы: стоимость услуги поручительства составляет $0,5-0,75 \%$ годовых, сумма поручительства не более 25 миллионов рублей, доля поручительства - до 50\% от суммы залога.

Также в Самарской области существует программа предоставления микрозаймов. Субъектам малого и среднего предпринимательства, которые осуществляют свою деятельность от шести месяцев и более предоставляются микрозаймы в размере, не превышающем 3 миллиона рублей. Срок предоставления займа составляет три года под 8\% годовых, обязательное условие - это обеспечение (банковская гарантия, залог или поручительство).

Региональными фондами финансовой поддержки субъектов МСП приняты ряд мер (рисунок 1), которые обеспечат доступ субъектов 

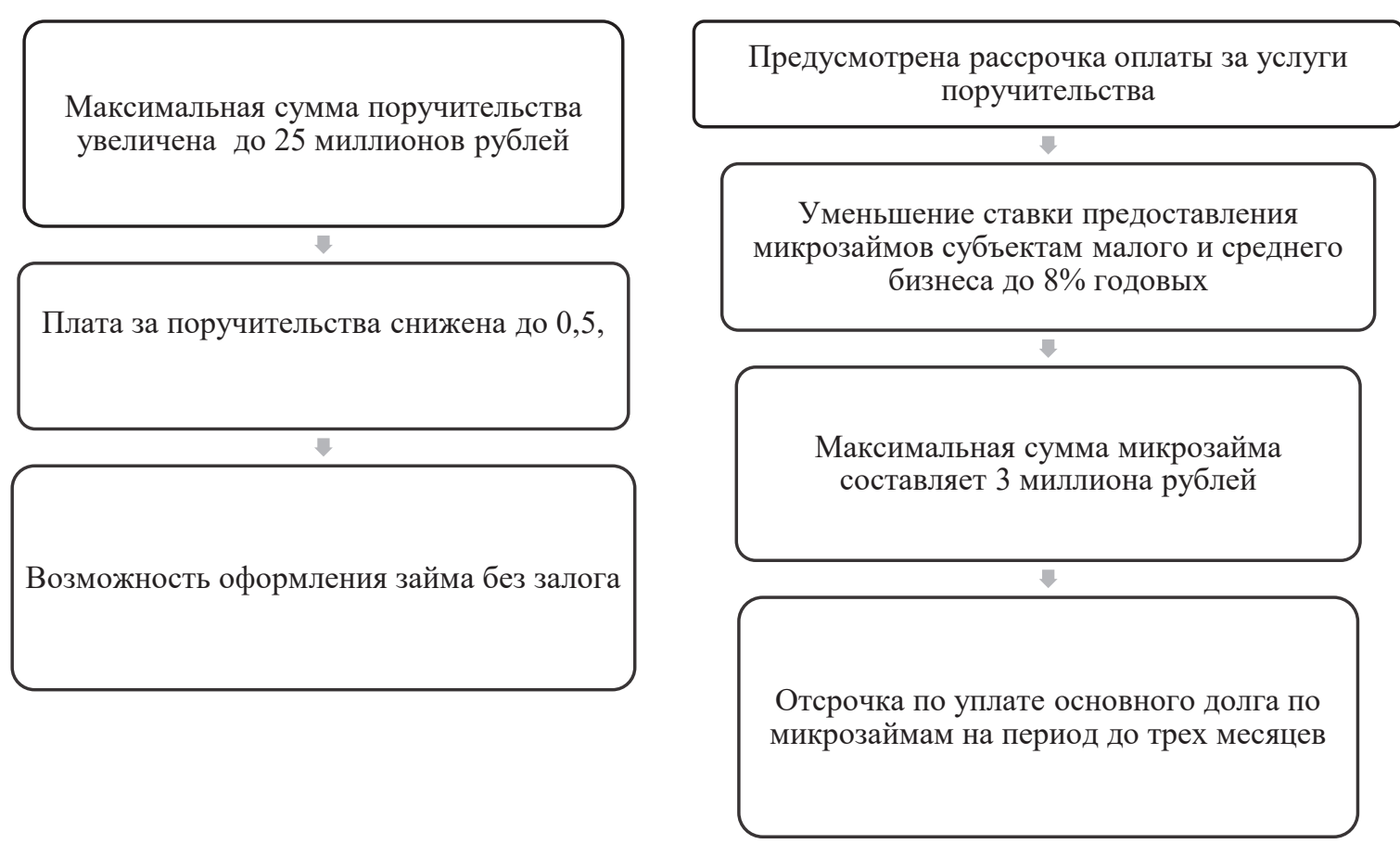

Рисунок 1. Меры региональных фондов финансовой поддержки субъектов МСП

малого и среднего предпринимательства к финансовым ресурсам.

Министерство экономики и развития Российской Федерации утвердил программу, согласно которой с 1 января 2018 года предприниматели могут оформить кредит по конечной ставке 6,5\% годовых. У субъектов малого и среднего предпринимательства есть возможность получить кредит на пополнение оборотных средств и инвестиционные цели. Согласно программе с льготной ставкой кредитования сумма кредита может варьироваться от трех миллионов до одного миллиарда рублей на инвестиционные цели со сроком кредита до 10 лет, а на пополнение оборотных средств - срок кредита 3 года и менее, сумма кредита от трех до ста миллионов рублей. В данной льготной программе кредитования участвуют 15 банков, включающие в себя такие крупные банка, как Сбербанк, ВТБ, Альфа-банк и другие.

Стоит отметить, что воспользоваться льготным кредитованием смогут не все предприятия. Так, приоритетными видами деятельности, позволяющими рассчитывать на льготы по кредиту, являются строительство, туризм, сельское хозяйство, обрабатывающие производства, деятельность в сфере здравоохранения, утилизация отходов.
Российский экспортный центр всячески оказывает содействие в поддержке малого и среднего предпринимательства. РЭЦ помогает решить вопрос по выходу малого и среднего бизнеса на экспорт путем расширения деятельности профильных институтов поддержки экспорта на региональном уровне. Российский экспортный центр оказывает не только консультационную поддержку, но организует и проводит различного вида обучающие программы, включающие в себя обучение ведения внешнеэкономической деятельности, а также участие субъектов малого и среднего предпринимательства в международных ярмарках-выставках.

Фонд «Региональный центр развития предпринимательства Самарской области», в свою очередь, также оказывает поддержку субъектам МСП. Так, в конце 2019 года Фонд запустил акселерационную программу «Энергия экспорта». Целью данной программы бизнес-акселератора является выход субъектов малого и среднего бизнеса на рынок Китая. Бизнес акселератор представляет собой курс семинаров-тренингов, спикерами данных семинаров являются действующие практики международного права, бизнес-консультанты, имеющие опыт ведения бизнеса в Китае и другие. Также программа включает в себя разбор проектов, бизнес-планов, 
их корректировка и расчет новой финансовой модели бизнеса обучающихся. Одним из ключевых моментов данной программы является заключение договора на тестовую партию продажи того или иного товара в Китай. Акселерационная программа проводится на платной основе, но субъектам малого бизнеса придется оплатить всего лишь 20\% от общей стоимости, все остальное компенсирует Фонд «Региональный центр развития предпринимательства Самарской области».

Фонд «Региональный центр развития предпринимательства Самарской области» оказывает содействие в организации участия субъектам малого и среднего предпринимательства в международных выставочно-ярмарочных и конгрессных мероприятиях на территории Российской Федерации и за ее пределами, в том числе: включение в состав делегации, обеспечении площадки, разработка макета застройки, транспортировка выставочных экспонатов, протокольное обеспечение участия. Данная поддержка малому предпринимательству актуальна для производственных предприятий. В Москве Фонд ежегодно организовывает выставку «ПродЭкспо» - международная выставка продуктов питания, напитков и сырья для их производства. У предпринимателей есть огромная возможность заявить о себе, представив свою продукцию на данной выставке. На подобных мероприятиях присутствуют не только потенциальные покупатели, но и заинтересованные люди, например, инвестиционные или венчурные фонды, готовые вложить инвестиции в интересующий их проект, а для начинающих предпринимателей и стартаперов - это шанс развить свой бизнес. Фонд проводит выставки продуктов питания, как уже отмечалось выше, не только в Российской Федерации, но и за ее пределами. Так, в мае 2019 года была организована выставка в Шанхае, куда смогли поехать многие предприниматели, в перспективе желающие выйти на экспорт в Китай. Хочется здесь отметить, что участие в подобного рода выставках за рубежом, обходится компании в 20\% от стоимости, $80 \%$ стоимости участия берет на себя Российский экспортный центр.

В Самарской области одним из главных направлений является развитие предпринимательства среди молодежи. Именно для достижения этой цели самарские власти реализовывают программу федерального значения под назва- нием «Ты предприниматель». На территории Самарской области «Ты - предприниматель» работает с 2015 года. Программа пришла в регион благодаря поддержке Министерства экономического развития, инвестиций и торговли Самарской области. За все время через нее прошли более 10 тысяч человек, порядка 3000 участников посетили образовательные программы, а каждый десятый - реализовал свой проект и продолжает развивать его сегодня. Среди участников - десятки предпринимателей, которые смогли перезагрузить свой проект или запустить его с нуля. За годы с программой сотрудничали более 120 экспертов. Для молодежного предпринимательства данная программа - возможность информационной обеспеченности, поддержки, возможность реализовать и усовершенствовать свою идею, а также получить базовые знания, как построить свой бизнес. Молодые граждане, которые хотят открыть свое дело проходят обучение, принимают участие в менторских сессиях, а также имеют возможность общения с действующими успешными бизнесменами, получая от них консультации в индивидуальном порядке.

В регионе для создания благоприятных условий для развития предпринимательства и для снижения административных преград, ведется огромная работа, а именно разрабатываются и внедряются предложения по внесению изменений в действующее российское законодательство.

В Самарской области приняты и действуют ряд законов, направленных на поддержку предпринимателей малого и среднего бизнеса. Среди таких законов необходимо отметить, так называемый закон о налоговых каникулах, который распространяется на определенную категорию налогоплательщиков, применяющих упрощенную или патентную систему налогообложения» [3].

Данный закон устанавливает льготную налоговую ставку для той категории предпринимателей, которые впервые зарегистрированы для осуществления своей деятельности по оказанию бытовых услуг населению, либо сфере производства продукции, научной или социальной сфере. Причем, данные предприниматели обязательно должны выбрать упрощенную систему налогообложения либо патентную.

Не менее значимым для субъектов малого и среднего предпринимательства, является закон Самарской области № 96-ГД от 11.07.2016, 
касающийся расширения перечня видов предпринимательской деятельности, имеющим возможность переведения на патентную систему налогообложения. Этот закон увеличивает число таких видов деятельности с 47 до 63 [4].

В Самарской области равно, как и в других регионах страны, широко распространена программа субсидирования малого и среднего предпринимательства. Министерство экономического развития, инвестиций и торговли Самарской области оказывает поддержку малому бизнесу в виде выплаты субсидий на различные цели. Данная программа организована на безвозмездной основе и распространяется на уплату таких статей расходов, как: лизинговые платежи; плата за услуги по предоставлению поручительства по кредитным договорам; грант на организацию собственного дела: на государственную регистрацию юридического лица или индивидуального предпринимателя; на покупку основных фондов и т.д.

Как уже отмечалось выше, для того, чтобы получить субсидию, предпринимателям необходимо пройти долгий и достаточно трудный путь.
Субсидирование осуществляется на конкурсной основе, заявку на получение субсидии необходимо подать в строго установленный срок. Далее необходимо собрать необходимый пакет документов, обосновать цель, для реализации которой требуются испрашиваемые денежные средства, подробный бизнес-план, в котором следует постатейно расписать все расходы, а также просчитать будущую прибыль. Также следует отметить, что деньги должны быть потрачены строго на указанные цели. В течение года после получения субсидии компаниям необходимо отчитываться за полученные деньги по установленным формам. Взамен на финансовую поддержку государство должно получить новые дополнительные рабочие места и прирост выручки, о чем будут свидетельствовать отчеты, предоставленные предпринимателями. Если по тем или иным причинам расходы окажутся нецелевыми и условия договора не будут выполнены, предприниматель рискует потерять эти деньги и вернуть субсидию государство. Также договором о субсидировании предусмотрена ответственность на невыполнение условий договора. Так, напри-
Субсидия инновационной компании

r

Приобретение машин и оборудования, связанных с технологическими инновациями

Приобретение новых технологий (в том
числе прав на патенты, лицензий на
использование изобретений,
промышленных образцов, полезных
моделей

Приобретение программных средств

\section{章}

Переподготовка и обучение сотрудников, связанных с инновациями

$\checkmark$

Уплата процентов по кредитам, полученным в российских кредитных организациях

$\checkmark$

Патентование и сертификация продукции.
Субсидия экспортообразующего предприятия

Уплата процентов по кредитам $\sqrt{2}$

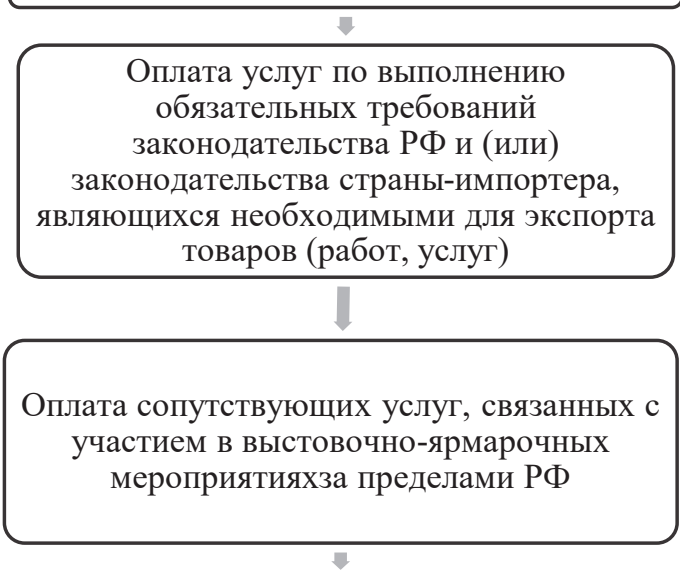

Оплата услуг по разработке средств индивидуализации юридического лица, индивидуализации продукции (работ, услуг), в том числе фирменного наименования, товарного знака, по созданию промышленного образца для товаров (работ, услуг), предназначенных для экспорта 
мер, если численность сотрудников не достигла определенного показателя, предпринимателям грозит штраф в размере процента (указанного в договоре) от суммы субсидии.

Хочется обратить внимание еще на одну меру государственной политики в сфере занятости населения - инициирование пилотного проекта по созданию особых налоговых условий для само занятых граждан. В этих целях с начала 2019 г. был введен на территории четырех субъектов РФ, таких как, Москва, Московская и Тверская области, и республика Татарстан, специальный налоговый режим, который рассчитан на 10 лет. По ходу реализации данного проекта, с учетом различных факторов, предусмотрена корректировка условий его проведения.

Самарская область, в развитие национального проекта «Малое и среднее предпринимательство и поддержка индивидуальной предпринимательской инициативы», с 1 января 2020 года запустила свой региональный проект по созданию особых налоговых условий для само занятых граждан.

Согласно данным статистических исследований, достаточно весомая часть населения страны, порядка 13\%, осуществляет различные виды предпринимательской деятельности, без необходимой регистрации в налоговых органах, тем самым лишая бюджет необходимых влияний. Чтобы ликвидировать данный пробел в законодательстве, проект призван помочь само занятым гражданам на льготных условиях зарегистрировать свою деятельность, и действовать в рамках закона РФ.

Национальный проект «Малое и среднее предпринимательство и поддержка индивидуальной предпринимательской инициативы» предназначен в первую очередь, оказывать необходимую юридическую, консультационную помощь начинающим бизнесменам н всех этапах их деятельности: от возникновения самой идеи начать свой бизнес до его глобализации с реальной возможностью выхода на международный рынок.

В результате реализации проекта само занятые получают весьма привлекательные, выгодные условия в части налогообложения. Речь идет, прежде всего, о фиксированной пониженной ставке налога на доход, освобождении от формирования и предоставления в налоговые органы излишней бухгалтерской и налоговой отчетности. К примеру, ставка налога на доходы при обслуживании физических лиц будет составлять 4\%, а при сотрудничестве с юридическими лицами всего 6\%, причем в эту ставку включены и обязательные отчисления в органы социального страхования.

Как подчеркнул председатель Правительства Самарской области В.Кудряшов «Предоставление особых условий для само занятых граждан это ещё одна мера государственной поддержки, которая должна привести к росту предпринимательской активности и в регионе, и в стране. Государство, снижая требования к людям, получающим профессиональный доход, даёт им возможность легализовать своё дело. Регистрация в качестве само занятого ни в коем случае не приведёт к дополнительной нагрузке, а наоборот, предоставит дополнительные преимущества».

Легальная, деятельность самозанятых несет для них определенные социальные гарантии, что немаловажно. Прежде всего, это учет трудового стажа, гарантированное медицинское обслуживание, возможность получение кредитов на более выгодных условиях, что гарантирует подтверждение трудового стажа. Ещё это хорошая возможность попробовать свои силы в предпринимательской деятельности. Начав заниматься бизнесом, как самозанятый, можно оценить свои силы и дальше развивать бизнес, перейдя на ИП или ООО.

Президентом РФ, в рамках ежегодного послания Совету Федерации в январе 2020 г.были предложены дополнительные меры поддержки бизнеса (рисунок 3).

Подводя итоги вышесказанному, можно сделать вывод, что государственная политика в отношении малого бизнеса в России с целью повышения занятости населения в настоящее время активно проводится. Разрабатываются и внедряются различные государственные программы по поддержке (финансовой, консультационной и т.д.) малого и среднего бизнеса, создаются новые рабочие места, сокращается уровень безработицы в стране. 
Стабильные налоговые условия на шесть и более лет
Регламентация работы контрольнонадзирательных органов
Гибкий режим правового регулирования
Повышение уровня инвестиционных вложений в приоритетные направления

Совершенствование программы льготного кредитования

Рисунок 3. Дополнительные меры поддержки бизнеса

\section{Библиографический список}

1. Государственная программа РФ «Содействие занятости населения», утверждена постановлением правительства РФ от 15 апреля 2014 года N 298 (с изменениями на 30 марта 2020 года).

2. Государственная программа Самарской области «Развитие предпринимательства, торговли и туризма в Самарской области» на 2014-2030 годы, утверждена постановлением Правительства Самарской области от 29.11.2013 № 699)

3. Закон Самарской Губернской Думы от 30.12.2015 № 140-ГД (в ред от 13.02.2017 № 20-ГД) «О налоговой ставке в размере 0 процентов для отдельных категорий налогоплательщиков - индивидуальных предпринимателей, применяющих упрощенную систему налогообложения и (или) патентную систему налогообложения»

4. Закон Самарской области от 11.07.2016 № 96-ГД «О внесении изменений в Закон Самарской области «О патентной системе налогообложения на территории Самарской области».

5. Федеральный закон «О развитии малого и среднего предпринимательства в Российской Федерации» от 24.07.2007 N 209-Ф3.

6. Данилова Т. С. Реализация государственной политики занятости на муниципальном уровне// Молодой ученый. 2016- № 11.- с 702-704.

7. Юсупова И.В.Приоритетные направления реализации государственной политики занятости в регионе // Профессиональное образование в России и за рубежом. 2016. - № 14.- С. 22.

8. «Паспорт национального проекта «Малое и среднее предпринимательство и поддержка индивидуальной предпринимательской инициативы» (утв. президиумом Совета при Президенте РФ по стратегическому развитию и национальным проектам, протокол от 24.12.2018 N 16).

9. Долгова А. Полная и эффективная занятость молодежи // Человек и труд.- М., 2015._ № 8.- С. 38.

10. Петров А.М. «КОНТРОЛЬ ЗА ДВИЖЕНИЕМ ДЕБИТОРСКОЙ И КРЕДИТОРСКОЙ ЗАДОЛЖЕННОСТИ» Современный бухучет. 2004. № 9. С. 38.

11. Карпова Т.П., Петров А.М., ГорбатковаГ.А., Самарина Л.Б., ДашкинаГ.Г., СидороваМ.И., Сабанин Р.Л., Ситникова В.А., ЛистопадЕ.Е. «БУХГАЛТЕРСКИЙ УЧЕТ В СФЕРЕ УСЛУГ» учебник для студентов высшего профессионального образования, обучающихся по специальности 080109 «Бухгалтерский учет, анализ и аудит» / Под редакцией М.А. Вахрушиной; Министерство образования и науки Российской Федерации, Федеральное государственное учреждение «Федеральный институт развития образования». Москва, 2011. Сер. Читай

12. Петров А.М., МельниковаЛ.А. «ФОРМИРОВАНИЕ ОТЧЕТНОСТИ В СООТВЕТСТВИИ С ТРЕБОВАНИЯМИ МСФО КАК ОБЪЕКТИВНАЯ НЕОБХОДИМОСТЬ НА СОВРЕМЕННОМ ЭТАПЕ РАЗВИТИЯ ЭКОНОМИКИ РФ» Проблемы современной экономики. 2017. № 2 (62). С. 105-107. 
13. Петров А.М., Коняхин А.Н. «УЧЕТНАЯ ПОЛИТИКА ПРИ ПОДГОТОВКЕ ПЕРВОЙ ОТЧЕТНОСТИ СОГЛАСНО МСФО» Международный бухгалтерский учет. 2013. № 11 (257). С. 2-15.

14. Петров А.М., Лымарь М. П. «СОСТАВ БУХГАЛТЕРСКОЙ ОТЧЕТНОСТИ В РОССИИ И КИТАЕ» МежДУНародНЫЙ бухгалтерский учет. 2014. № 31 (325). С. 28-37.

15. Петров А.М., ЛЫМарь М.П. «СРАВНИТЕЛЬНАЯ ХАРАКТЕРИСТИКА ОСНОВНЫХ ПОЛОЖЕНИЙ ЗАКОНОВ, РЕГУЛИРУЮЩИХ БУХГАЛТЕРСКИЙ УЧЕТ В КИТАЕ И РОССИИ» МеЖдУНароднЫЙ бухгалтерский учет. 2013. № 40 (286). C. 52-60.

16. Петров А.М., ЛЫмарь М.П. «СРАВНИТЕЛЬНЫЙ АНАЛИЗ БУХГАЛТЕРСКОГО УЧЕТА АКТИВОВ В РОССИИ И КИТАЕ» Международный бухгалтерский учет. 2014. № 27 (321). С. 34-48. 